\title{
Acute tissue ischemia after implantable loop recorder replacement
}

\author{
Aurora Sanniti ${ }^{1}$ (D) Domenico Zagari ${ }^{1}$. Elvira Renzullo ${ }^{1}$. Veronica Arlant ${ }^{1} \cdot$ Paolo Moretti $^{1}$. Giammario Spadacini ${ }^{1}$. \\ Massimo Tritto $^{1,2}$
}

Received: 14 September 2021 / Accepted: 27 January 2022 / Published online: 7 February 2022

(C) The Author(s), under exclusive licence to Springer Science+Business Media, LLC, part of Springer Nature 2022

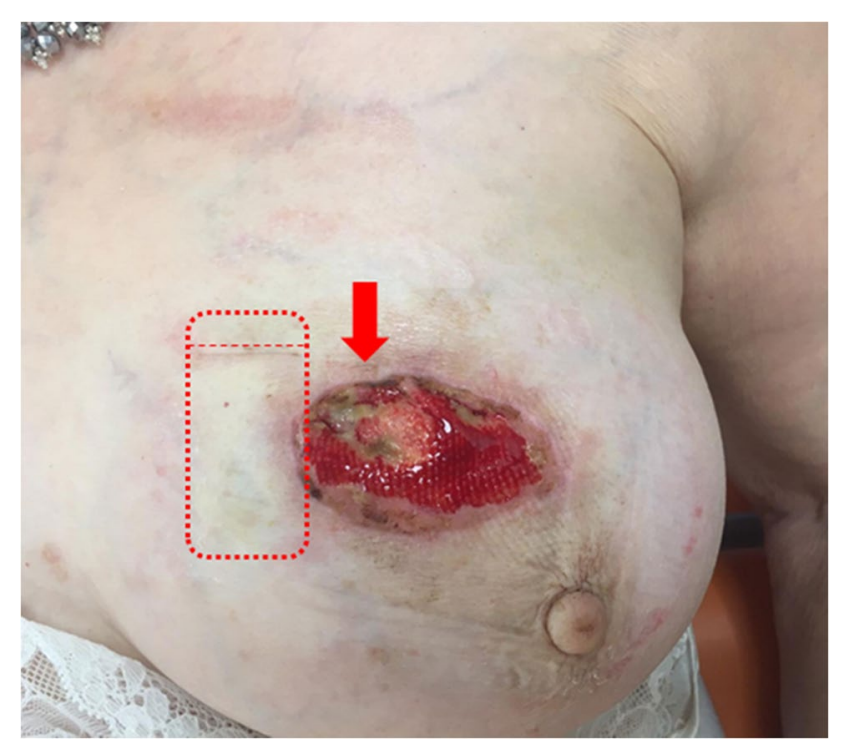

We present the uncommon case of an implantable loop recorder replacement complicated by tissue ischemic damage in a woman aged 84 with diabetes, hypertension, and permanent atrial fibrillation. The new device was the same model as the previous one (Reveal XT, Medtronic), and the original pocket was only minimally reshaped through subcutaneous dissection and electrocautery. The skin surface appeared intact at the time of discharge. One week later, just lateral to the device pocket, the patient noted an ulcerative lesion of the skin increasing in size during the following days. A thick eschar was removed at the first medical contact, revealing a necrotic area in strict proximity to the superolateral aspect of the device pocket (arrow). The surgical wound was in order without evidence of local or systemic infection (no erythema, no heat, no swelling, no pus, no continuity solution along the incision, no fever, no flogosis index on blood tests). The lesion was cleaned with moist care once a week for 2 months and healed secondarily. A tumoral nature of the ulcerative lesion was excluded by echo. An allergic reaction to the protective patch was also considered, but the localization of the lesion made this explanation unlikely. In that instance, the lesion would have followed the patch contour. Given the time matching with the replacement procedure, we hypothesized an acute ischemic injury fostered by diabetes and a suboptimal cleavage plane. Indeed, an improper or extensive undermining in a superficial plane can harm the dermal plexus (the main blood supply to the skin) causing acute tissue ischemia and necrosis [1].

\section{Reference}

1. Delaney A, Diamantis S, Marks VJ, et al. Complications of tissue ischemia in dermatologic surgery. Dermatol Ther. 2011;24(6):551-7.

Publisher's note Springer Nature remains neutral with regard to jurisdictional claims in published maps and institutional affiliations.

Aurora Sanniti

aurora.sanniti@libero.it

1 Electrophysiology and Pacing Unit, Humanitas

Mater Domini Clinical Institute, Via Gerenzano, n.2,

21053 Castellanza, Varese, Italy

2 Department of Biomedical Sciences, Humanitas University,

Pieve Emanuele, Milan, Italy 